\title{
ASSESSMENT OF 0.3-ML MINIVIALS FOR RADIOCARBON DATING BY LIQUID SCINTILLATION COUNTING OF BENZENE
}

\author{
A. G. HOGG
}

\author{
Radiocarbon Dating Laboratory, The University of Waikato, Hamilton, New Zealand
}

\begin{abstract}
I have made an evaluation of $0.3-\mathrm{ml}$ minivials for ${ }^{14} \mathrm{C}$ dating of small samples by liquid scintillation counting of benzene. A calibrated wood standard was diluted by varying amounts of ancient $\mathrm{CO}_{2}$, with synthesized benzene counted in both conventional $3.0-\mathrm{ml}$ vials and $0.3-\mathrm{ml}$ minivials in a 1220 Quantulus. The accuracy and precision of results are compared for samples ranging in weight from 50 to $240 \mathrm{mg}$ of carbon. I examined two significant potential problems associated with handling small samples, namely, memory effects within the vacuum system, and signal within the dilution gas. Although accurate radiocarbon dates can be obtained using either standard vials or minivials, minivials are more suitable for dating small samples because they are less influenced by these sources of error.
\end{abstract}

\section{INTRODUCTION}

The best modern low-level liquid scintillation (LS) spectrometers have ${ }^{14} \mathrm{C}$ counting efficiencies exceeding $80 \%$, and ultra-low backgrounds as little as $0.8 \%$ of the ${ }^{14} \mathrm{C}$ reference signal (e.g., Polach et al. 1988a; Hogg et al. 1991). The potential for small-sample radiocarbon dating using LS spectroscopy is one application of these reduced background levels (e.g., Polach et al. 1988b).

The LS method generally utilizes 2.4-6 g C in 3.0- or 7.0-ml counting vials (Polach et al. 1988b). In small-sample dating, where less carbon is available, many laboratories have traditionally diluted samples with either ancient $\mathrm{CO}_{2}$ or benzene. More recently, however, minivials of $0.3-\mathrm{ml}$ volume have been developed (Devine \& Haas 1987; Polach et al. 1988b), with superior counting characteristics for sample sizes $<240 \mathrm{mg}$ C. Although published modern and background count rates have enabled calculation of the precision to be expected from minivials (e.g., Polach et al. 1988b), no attempt has been made to determine their accuracy. Such an attempt should proceed beyond vial parameters alone, to embrace total laboratory procedures.

I show here tests on $0.3-\mathrm{ml}$ minivials, by analyzing the accuracy and precision of dates obtained from a calibrated wood standard, varying in size from 50 to $240 \mathrm{mg} \mathrm{C}$, in both $0.3-\mathrm{ml}$ minivials and traditional $3.0-\mathrm{ml}$ counting vials, and also highlight two potential sources of error in handling very small samples.

\section{EXPERIMENTAL}

I used a calibrated wood standard (Glasgow wood - 2185 BP), supplied by the Glasgow University intercalibration project in this study (Aitchison et al. 1990). The absolute date of the sample was determined by the Belfast dendrochronological laboratory at 241-260 BC (Scott et al. 1990). This corresponds to a radiocarbon age of 2220-2160 cal BP, using the calibration data of Pearson et al. (1986). A nominal ${ }^{14} \mathrm{C}$ age of $2185 \mathrm{BP}$ is shown in Figures 1 and 2.

I made measurements in a Wallac 1220 Quantulus spectrometer, using Wallac 3.0-ml teflon-copper vials and experimental $0.3-\mathrm{ml}$ teflon minivials, also made by Wallac (Polach et al. $1988 \mathrm{~b}$ ). ${ }^{14} \mathrm{C}$ ages are calculated for three sample weights $(50,120$ and $240 \mathrm{mg} \mathrm{C})$ in each vial, with undersized samples diluted with ancient $\mathrm{CO}_{2}$. The dilution gas is high-purity $\mathrm{CO}_{2}$ stripped from natural gas, derived from the Kapuni Gas Field in New Zealand. 


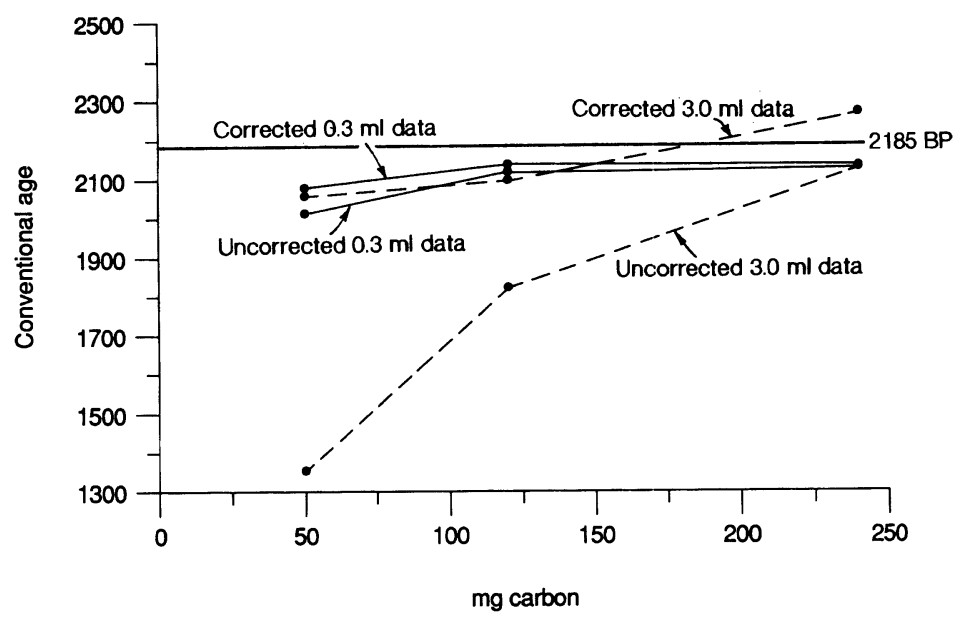

Fig. 1. Initial and corrected ${ }^{14} \mathrm{C}$ ages of the Glasgow wood standard for 50,120 , and $240 \mathrm{mg} \mathrm{C}$ in 3.0 - and 0.3 -ml vials. The horizontal line represents the nominal age for the standard (2185 BP).

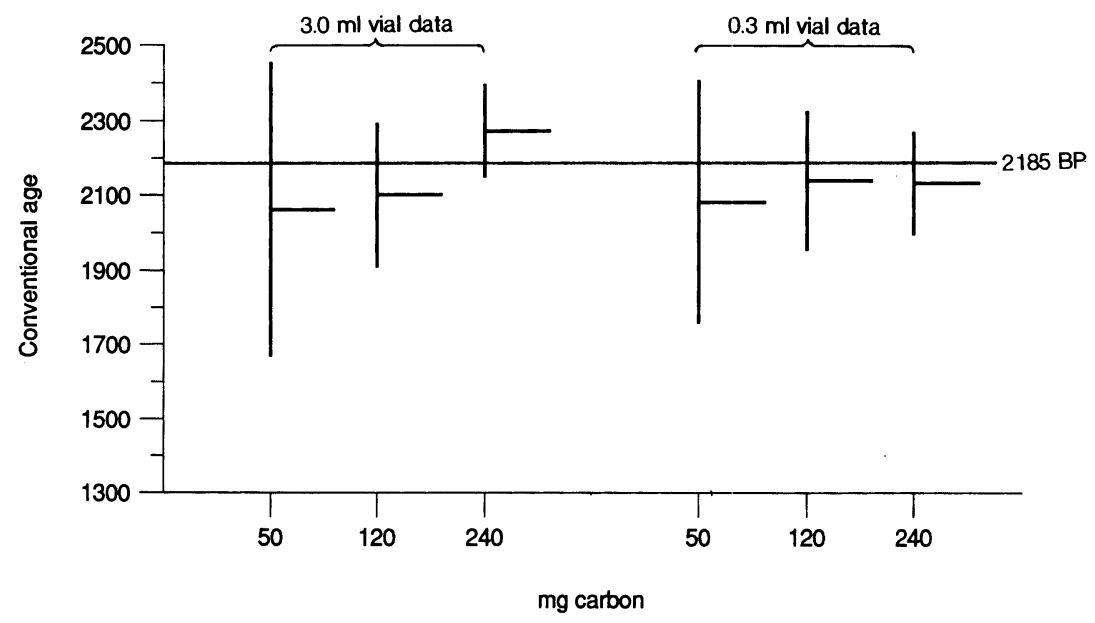

Fig. 2. Corrected conventional ages of the Glasgow wood standard (2185 BP - horizontal line) for 50, 120, and $240 \mathrm{mg}$ $\mathrm{C}$ in both 3.0- and 0.3-ml vials. The error bars denote $1 \mathrm{o}$ errors.

The 3.0-ml vials were standardized for $3.0 \mathrm{ml}$ of benzene ( $2.637 \mathrm{~g}$ benzene), using analytical-grade reagent benzene ${ }^{1}$ and the modern secondary reference standard, ANU sucrose (Currie \& Polach 1980). Similarly, the $0.3-\mathrm{ml}$ vials were standardized for $0.3 \mathrm{ml}$ of benzene ( $0.2637 \mathrm{~g}$ benzene) with the same standard materials. All samples were analyzed for $3000 \mathrm{~min}$, with standard errors based upon 3000-min background and reference counting times.

The vacuum lines required for the conversion of $\mathrm{CO}_{2}$ to benzene were prepared for low-activity measurements by processing a train of ancient samples in a specific order designed to eliminate, largely, memory effects from previous samples. The order of analysis was: ancient swamp kauri,

${ }^{1}$ In this paper, analytical-grade reagent (AR) benzene, used directly in the counting vials to establish background levels, is distinguished from synthesized (syn) benzene, which is generated in the laboratory by combusting AR benzene. 
synthesized benzene 1 , synthesized benzene 2 , a background oxalic acid standard containing no ${ }^{14} \mathrm{C}$, marble and lastly, dilution gas.

\section{RESULTS AND DISCUSSION}

Table 1 shows ${ }^{14} \mathrm{C}$ age determinations for 50,120 and $240 \mathrm{mg} \mathrm{C}$ for both 3.0 - and $0.3-\mathrm{ml}$ vials. The initial results obtained for the $3.0-\mathrm{ml}$ vials showed ages up to two standard deviations too young.

TABLE 1. Conventional ages of the Glasgow calibrated wood sample (2185 BP) for various sample sizes in traditional 3.0- and $0.3-\mathrm{ml}$ minivials. All measurements based upon 3000-min counting times for both sample and standards.

\begin{tabular}{lllllcc}
\hline $\begin{array}{l}\text { Vial } \\
\text { size } \\
(\mathrm{ml})\end{array}$ & $\begin{array}{l}2 \\
\text { Percent } \\
\text { dilution } \\
\text { gas }\end{array}$ & $\begin{array}{l}3 \\
\text { Sample } \\
\text { size } \\
(\mathrm{mg} \mathrm{C})\end{array}$ & $\begin{array}{l}4 \\
\text { Initial } \\
\text { uncorrected age } \\
(\mathrm{yr} \mathrm{BP})\end{array}$ & $\begin{array}{l}5^{*} \\
\text { Background } \\
\text { corrected age } \\
(\mathrm{yr} \mathrm{BP})\end{array}$ & $\begin{array}{l}6^{* *} \\
\begin{array}{l}\text { Dilution gas } \\
\text { corrected age } \\
(\mathrm{yr} \mathrm{BP})\end{array}\end{array}$ & $\begin{array}{l}7 \\
\begin{array}{l}\text { Final } \\
\text { corrected age } \\
(\mathrm{yr} \mathrm{BP})\end{array}\end{array}$ \\
\hline 3.0 & 90 & 240 & $2135 \pm 117$ & $2177 \pm 118$ & $2229 \pm 121$ & $2272 \pm 122$ \\
& 95 & 120 & $1824 \pm 175$ & $1907 \pm 179$ & $2015 \pm 186$ & $2100 \pm 189$ \\
& 98 & 50 & $1354 \pm 333$ & $1559 \pm 347$ & $1841 \pm 375$ & $2060 \pm 390$ \\
0.3 & 0 & 240 & $2131 \pm 131$ & $2133 \pm 131$ & $2131 \pm 134$ & $2133 \pm 134$ \\
& 50 & 120 & $2121 \pm 172$ & $2128 \pm 174$ & $2132 \pm 182$ & $2139 \pm 183$ \\
& 80 & 50 & $2014 \pm 276$ & $2035 \pm 282$ & $2060 \pm 316$ & $2081 \pm 322$ \\
\hline
\end{tabular}

*Background correction based upon syn benzene activity of $4.12 \times 10^{-3} \pm 8.62 \times 10^{-4} \mathrm{cpm}$

**Dilution-gas correction based upon dilution-gas activity of $9.70 \times 10^{-3} \pm 2.46 \times 10^{-3} \mathrm{cpm}$

\section{Sources of Error}

Initial uncorrected ${ }^{14} \mathrm{C}$ ages (for the 3.0-ml vials in particular, Table 1, Column 4), show errors that clearly increase with the degree of dilution. Two factors are responsible for this - memory effects in the vacuum system and a small signal in the dilution gas.

Memory Effects. Memory effects in the vacuum systems provide a potential source of error. This was quantified by combusting $\mathrm{AR}$ benzene in a gas bubbler, and converting the $\mathrm{CO}_{2}$ back to benzene in the normal manner. The measured activity for the syn benzene is $c a .0 .04 \mathrm{pMC}$ (Table $\left.1,{ }^{*}\right)$. This effect artificially elevates sample activity, and the error is magnified in proportion to the degree of dilution. The initial ages for memory effect are shown in Table 1, Column 5 ("Background corrected age").

Dilution Gas. Analysis of the Kapuni dilution $\mathrm{CO}_{2}$ revealed a significant source of activity, amounting to $c a .0 .1 \mathrm{pMC}$ (Table $1,{ }^{* *}$ ), possibly the result of contamination from modern $\mathrm{CO}_{2}$ during separation. This activity also artificially elevates sample activity. The effect of this error is seen in Table 1, Column 6, which shows initial ages corrected for the dilution gas activity ("Dilution gas corrected age").

When the proportion of dilution gas in any sample exceeds $c a .90 \%$, the sources of error described above result in a significant underestimation of age. Although $0.3-\mathrm{ml}$ minivials are subject to the same sources of error as their $3.0-\mathrm{ml}$ counterparts, the lower proportion of dilution gas (e.g., $50 \%$ for $120 \mathrm{mg} \mathrm{C}$ in $0.3-\mathrm{ml}$ minivials, $c f .95 \%$ for $3.0-\mathrm{ml}$ vials) results in substantially lower errors. 


\section{Comparative Accuracy of 3.0- and 0.3-ml Vials}

${ }^{14} \mathrm{C}$ ages corrected for both background and dilution gas effects are given in Table 1, Column 7 ("Final corrected age"), and compared with the "initial age" in Figure 1. Corrected conventional ages, including their standard errors, for both vials are presented in Figure 2.

All corrected results lie within $1 \sigma$ of the nominal age, thus validating the use of both standard $3.0-\mathrm{ml}$ vials and minivials. However, the background memory and dilution-gas effects are far less significant in the minivials. If the contributions of these types of error to sample activities are not precisely known, or are variable (as may be the case with background memory effects), accurate dates are more likely to be achievable for small samples, using minivials.

\section{Comparative Precision of 3.0- and 0.3-ml Vials}

The magnitude of the standard errors for the Glasgow wood shows little variation between the two sets of measurements (Table 1 \& Fig. 2). However, higher precision is achieved in the minivials with older samples, particularly when sample weights are $<240 \mathrm{mg} \mathrm{C}$ (e.g., for a sample containing $120 \mathrm{mg} \mathrm{C}$, use of the minivials would result in a $15 \%$ lowering of 1 o errors at $5 \mathrm{ka}$, and a $44 \%$ reduction at $20 \mathrm{ka}$ ).

Sample size limits of $100 \mathrm{mg} \mathrm{C}$ have been set for routine dating at the Australian National University (ANU) by Polach et al. (1988b). This produces an error of $\pm 200 \mathrm{yr}$ at Modern, and an old age limit of $25 \mathrm{ka}$ for 3000-min counting times. Standard errors for the three sample weights used in this study are plotted against sample age in Figure 3A, and are expressed as a percentage of the sample age in Figure 3B. The graph shows an optimum range, which will vary, depending upon application, for which minivials are most useful. Data for $50 \mathrm{mg} \mathrm{C}$ suggested limited application for routine dating purposes.

Small-sample LS spectrometry cannot seriously challenge accelerator mass spectrometry (AMS) dating in terms of precision for samples $<240 \mathrm{mg} \mathrm{C}$, but it can provide a cost-effective alternative for studies not requiring maximum precision ( $c f$. the $240 \mathrm{mg} \mathrm{C}$ minivial sample error of $\pm 134 \mathrm{vs}$. ca. \pm 70 for AMS (data from Scott et al. 1990) and ca. \pm 40 for $2400 \mathrm{mg} \mathrm{C}$ (i.e., $3 \mathrm{ml}$ benzene) by a Quantulus spectrometer using 3000-min counting times).

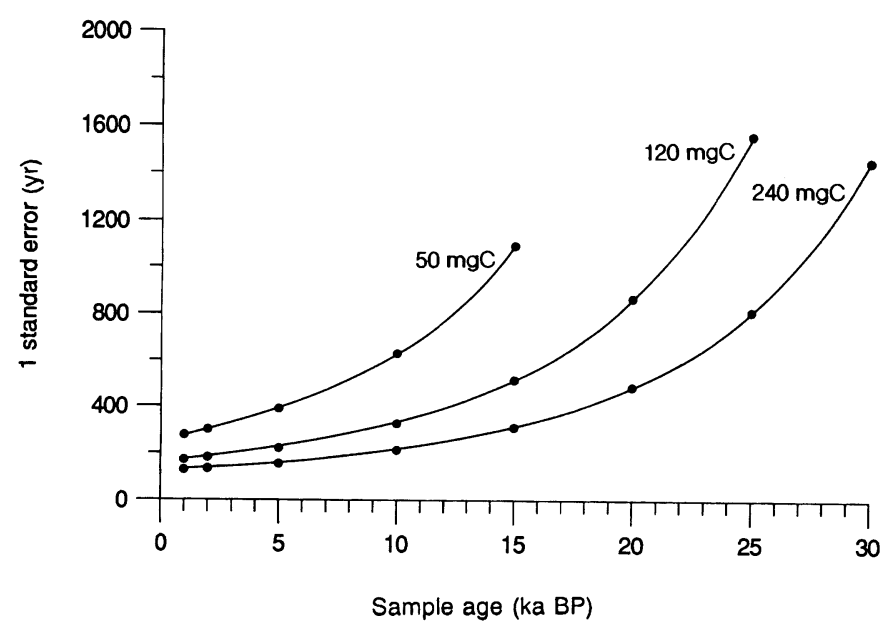

Fig. 3A. Plot of standard error against sample age for $0.3-\mathrm{ml}$ vials 


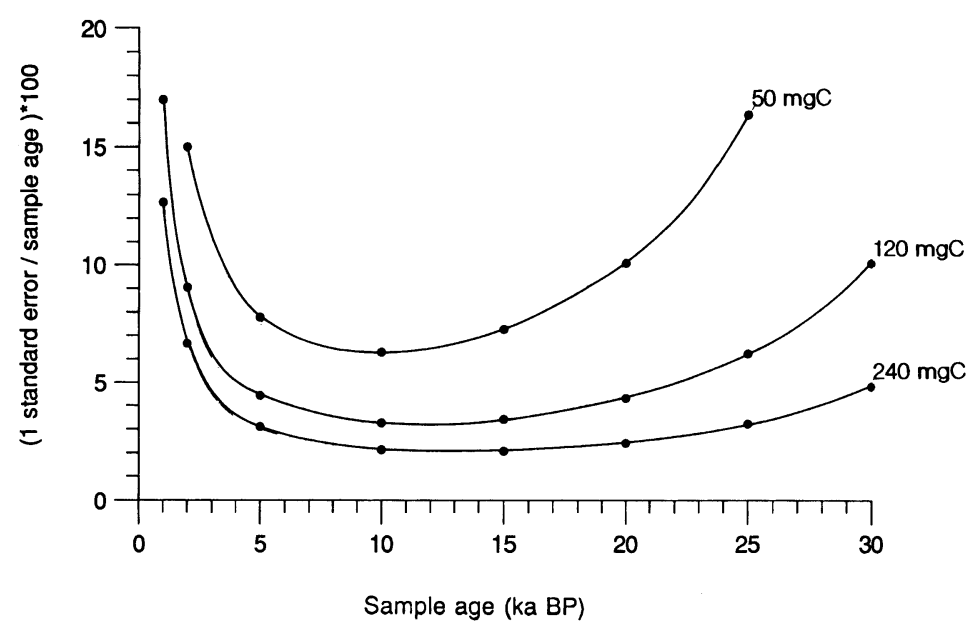

Fig. 3B. Standard error expressed as a percentage of sample age, $v s$. age for $0.3-\mathrm{ml}$ vials

\section{CONCLUSIONS}

Although accurate radiocarbon dates can be obtained using either standard or minivials, minivials are more suitable for dating small samples because they are less influenced by background memory and dilution gas activity. Where small sample sizes require a high level of gas dilution (i.e., where the proportion of dilution gas exceeds $90 \%$ ), significant underestimation of age can be expected. As a result of this study, I recommend the use of minivials for very small-sample radiometry, as they eliminate the need for high dilution, and provide more accurate results without the necessity of applying extensive correction factors.

\section{ACKNOWLEDGMENTS}

I would like to thank H. Polach, S. Robertson (ANU), K. Mackay and T. Higham (University of Waikato) for their critical comments.

\section{REFERENCES}

Aitchison, T. C., Scott, E. M., Harkness, D. D., Baxter, M. S. and Cook, G. T. 1990 Report on Stage 3 of the international collaborative program. In Scott, E. M., Long, A. and Kra, R. S., eds., Proceedings of the International Workshop on the Intercomparison of ${ }^{14} \mathrm{C}$ Laboratories. Radiocarbon 32(3): 271-278.

Currie, L. A. and Polach, H. A. 1980 Exploratory analysis of the international radiocarbon cross-calibration data: Consensus values and interlaboratory error. In Stuiver, M. and Kra, R. S., eds., Proceedings of the 10th International ${ }^{14} \mathrm{C}$ Conference. Radiocarbon 22(3): 933-935.

Devine, J. M. and Haas, H. 1987 Scintillation counter performance at the SMU Radiocarbon Laboratory. Radiocarbon 29(1): 12-17.

Hogg, A., Polach, H., Robertson, S. and Noakes, J. 1991 Application of high purity synthetic quartz vials to liquid scintillation low-level ${ }^{14} \mathrm{C}$ counting of benzene. In Ross, H., Noakes, J. E. and Spaulding, J. D., eds., Liquid Scintillation Counting and Organic
Scintillators. Chelsea, Michigan, Lewis Publishers, Inc.: 123-131.

Pearson, G. W., Pilcher, J. R., Baillie, M. G. L., Corbett, D. M. and Qua, F. 1986 High-precision ${ }^{14} \mathrm{C}$ measurement of Irish Oaks to show the natural ${ }^{14} \mathrm{C}$ variations from $A D$ 1840-5210 BC. In Stuiver, M. and Kra, R. S., eds., Proceedings of the 12th International ${ }^{14} \mathrm{C}$ Conference. Radiocarbon 28(2B): 911-934.

Polach, H. A., Calf, G., Harkness, D., Hogg, A. G., Kaihola, L. and Robertson, S. 1988a Performance of new technology liquid scintillation counters for ${ }^{14} \mathrm{C}$ dating. Nuclear Geophysics 2: 75-79.

Polach, H. A., Kaihola, L., Robertson, S. and Haas, H. $1988 \mathrm{~b}$ Small sample ${ }^{14} \mathrm{C}$ dating by liquid scintillation spectrometry. Radiocarbon 30(2): 153-155.

Scott, E. M., Aitchison, T. C., Baxter, M. S., Cook, G. T. and Harkness, D. D. 1990 C14 Cross Check: International Collaborative Study Report. Internal publication of Glasgow University: $175 \mathrm{p}$. 